\title{
Use of Back Propagation Artificial Neural Network to Predict Passenger Volume of Beijing Subway
}

\author{
Xiaoqing Zhang, Zhili Liu, Lan Li \\ MOE Key Laboratory for Urban Transportation Complex Systems Theory and Technology \\ Beijing Jiaotong University \\ Beijing, China \\ liuzl@bjtu.edu.cn;13120933@bjtu.edu.cn;13120861@bjtu.edu.cn
}

\begin{abstract}
This paper analyze different aspects of factors that affecting passenger volume of Beijing subway, then select fifteen key factors from four aspects: internal structure of the urban rail transit system, urban demographic features, economic development and urban transport structure. Firstly, SPSS software is used to examine the multicollinearity among all the variables and then we remove three factors that are of strong multicollinearity with others. Finally, B-P artificial neural network model is established based on the remainder of factors to predict passenger volume of Beijing subway for the next few years. The results show that the average relative error of the past twenty year is $5.56 \%$.
\end{abstract}

Keywords-passenger volume prediction of Beijing subway; SPSS; B-P artificial neural network

\section{INTRODUCTION}

With the accelerated pace of urbanization, motorization and modernization, the development of transportation in Beijing faces similar problems with other international metropolis like New York, Tokyo, Seoul and so on. Rapid growth of private cars, traffic congestion and severe haze are three serious problems remain to solve. In order to change this situation, Transportation development and construction planning of the twelfth Five-Year period were published by Beijing municipal government to accelerate the construction of rail transit and make sure the rail transportation become backbone of urban public passenger transport system.

Urban rail transit plays a key role in guiding and supporting optimization and adjustment of urban spatial structure. Priority to the development of urban public transport systems, efficiency improvement and raise of modal share of public transport are essential to ease problems of urban gridlock and air and noise pollution caused by the use of private cars. The accuracy of prediction has a direct impact on relevant departments to formulate long-term planning, improve the operational efficiency of urban rail transit system, develop a reasonable ticket fare and increase operating income system.

Because of the relevance of the subject and its direct connection with the quality of life, this study aims to contribute to providing a reliable method to predict subway passenger volume. In Section 2, we collect related data of the past twenty years and process preliminarily by SPSS software. In Section 3, we present the whole B-P artificial neural network prediction process. The results are presented in Section 4. Finally, conclusions are drawn in Section 5.

\section{ANALYSIS OF FACTORS AND DATA COLLECTION}

\section{A. Analysis of various factors}

By analyzing the level of urban development in Beijing as well as the current transport structure, we select factors that having influence on Beijing subway passenger volume from the following four aspects:

1) Internal structure of the urban rail transit system: the number of subway lines, length of subway lines, the number of subway vehicles.

2) Competing transport modes and their structures: the number of public buses, the number of bus lines, length of bus lines, bus passenger volume, the number of taxis, taxi passenger volume, the number of bicycle.

3) Urban demographic features: urban and suburban resident population, employed population, floating population.

4) Income and expenditure situation: per capita income, per capita transportation and communication expenditure.

\section{B. Data collection}

We collect data from Beijing statistical yearbooks of recent years as well as other information from Beijing Traffic Management Bureau and some relevant departments. There is a total of 20 years of data from year 1993 to 2012. They are shown in Table IV and Table V.

\section{Analysis of multicollinearity}

During the process of practical forecasting, the dependent variable is subject to the combined effect of many factors and it needs to be explained by a plurality of independent variables, however, multicollinearity may exist between them and they cannot be allowed to enter the model totally, therefore we are to analyze them first and remove factors which are of strong multicollinearity with others.

We use SPSS regression analysis to exclude variables whose regression coefficients are not significant during the 
significant test in each aspect. Here the dependent variable is subway passenger volume, variables are selected respectively from the four aspects, the method we choose is

TABLE I. REMOVED FACTORS

\begin{tabular}{|l|l|}
\hline \multicolumn{1}{|c|}{ Aspect } & \multicolumn{1}{c|}{ Removed variables } \\
\hline $\begin{array}{l}\text { Internal structure of the urban rail } \\
\text { transit system }\end{array}$ & Length of subway lines \\
\hline $\begin{array}{l}\text { Competing transport modes and } \\
\text { their structures }\end{array}$ & Length of bus lines \\
\hline Urban demographic features & Employed population \\
\hline Income and expenditure situation & None \\
\hline
\end{tabular}

\section{B-P NEURAL Network Predicting Process}

B-P model is a forward multilayer back-propagation neural network learning algorithm and it has become the most important and widely used learning algorithm that training feedforward neural network nowadays. The neural network can preferably solve the nonlinear problem. In this paper, we will use the neural network tool kit provided by Matlab 2014 and establish a three-layer B-P artificial neural network model to forecast passenger volume of Beijing subway for the next five years.

\section{A. Modeling idea of B-P artificial neural network}

Firstly, we see all the intricate factors that having influence on passenger volume of Beijing subway as a big system, then draw multilevel hierarchical structure according to the direct or indirect relationships of the elements in this system to describe the relationship between various elements.

The twelve variables constitute the input layer of the B-P artificial neural network, four aspects form the hidden layer and subway passenger volume is the output layer. Finally we establish a three-layer B-P artificial neural network model. As shown in Fig. 1.

\section{B. Numerical fitting process}

In this model we assume that the subway passenger volume is related with twelve variables, corresponding predictions of the twelve variables need to be obtained before predicting the subway passenger volume in the next five years. In order to ensure the accuracy of the predictions, we adopt the fitting function rather than a single linear regression method or the growth rate method, because deviation of the fitting function is smaller than other methods. The software we use is Matlab 2014 and the following is an example of the fitting process of subway vehicles number. backward selection and the results are shown in Table I, it can be seen that twelve variables remain eventually.

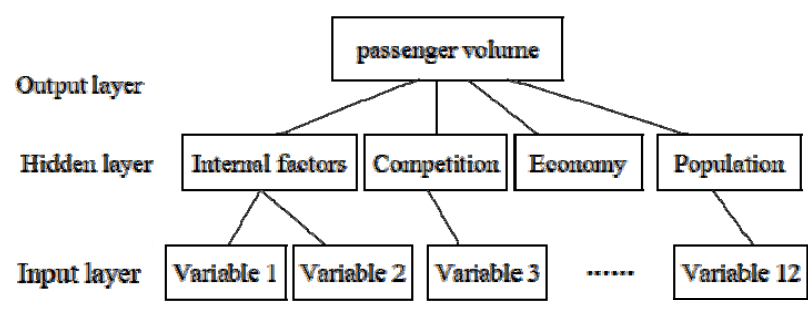

Figure 1. Structure of the prediction model.

Firstly, draw a scatter plot of the data;

Secondly, draw fitting curves of different degrees based on the scatter plot;

Thirdly, compare the three main curves shown in Fig.2, here we choose 4th degree polynomial because it fits the scatter plot well.

The fitting function of the variable : The number of subway vehicles is

$$
y_{8}=0.059 x^{4}-1.3 x^{3}+10 x^{2}-3.1 x+310
$$

We can also obtain fitting functions of the other eleven variables according to this method.

- The number of public buses:

$$
y_{1}=0.0071 x^{4}-0.36 x^{3}+5.8 x^{2}-23 x+70
$$

- The number of bus lines:

$$
y_{2}=0.5 x^{2}+16 x+200
$$

- Bus passenger volume:

$$
y_{3}=0.0046 x^{4}+0.16 x^{3}-7.8 x^{2}+190 x+2600
$$

- The number of taxis:

$$
y_{4}=0.35 x^{3}-13 x^{2}+150 x+55
$$

- Taxi passenger volume: $y_{5}=19 x+370$

- The number of bicycle: $y_{6}=0.57 x^{2}+25 x+690$

- The number of subway lines: $y_{7}=0.0054 x^{3}-0.12 x^{2}+0.72 x+0.92$

- Urban and suburban resident population: $y_{9}=1.8 x^{2}+3.4 x+820$

- Floating population: $y_{10}=0.75 x^{2}+2.3 x+160$

- $\quad$ Per capita income: $y_{11}=0.6 x^{2}+2.9 x+26$

- Per capita transportation and communication expenditure:

$y_{12}=-0.78 x^{3}+34 x^{2}-230 x+510$ 


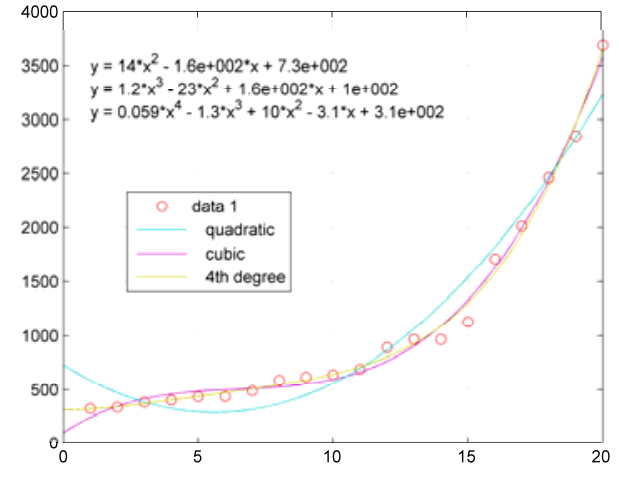

Figure 2. Fitting function.

\section{Prediction process}

1) Read sample data: Reads the input and output data of twenty samples we have collected as well as the twelve fitting functions from a text file, it will establish a B-P artificial neural network with twelve input variables, four hidden layer nodes, one forecasting target, B-P algorithm is then used to train the network and the computer will generate a nonlinear mapping model internally about the original data and relevant indexes. Use this model to forecast subway passenger volume.

2) Transfer function: Neighboring layers of the B-P artificial neural network are connected together by a transfer function. In general, the input layer and the hidden layer use the S-type function. There are two common S-type functions to be used, logsig is a logarithmic function that can generate $(0,1)$ output, while tansig is a tangent function that generate $(-1,1)$ output, we use tansig as transfer function for testing here because tansig converges faster than logsig. We adopt purelin which is a linear function and can generate the output of any range for the output layer.

3) Data preprocessing: When the input data are between 0 and 1 , learning efficiency and convergence speed of the network will be enhanced greatly. As we can see, the largest number we input is no more than 6000, dividing each number in the sample data by 8000 . After the conversion, we can ensure that any data is less than 1 . In the meanwhile, there left space between 6000 and 8000 to prevent overflow caused by the increase of the forecast data. Set the precision up to 0.0001 , take 50 times as learning step and take 80,000 times as the maximum number of iterations. When the precision reaches 0.0001 or the iteration number reached 80000 times, the software will output predictions and draw the fitting chart.

\section{4) Key Code}

gwwnet=newff(minmax(inputSampledata),[4,1],\{'tansig', 'purelin'\},'traingdm');

gwwnet.trainParam.show $=50$;

gwwnet.trainParam.lr = 0.05;
gwwnet.trainParam.epochs $=80000$; gwwnet.trainParam.goal = 1e-4;

\section{RESUlTS}

The biggest advantage to use the tansig function is its fast convergence speed. Experiments show that the prescribed precision can be achieved within 4-5 million times which is shown in Fig.3. And the fitting curve is shown in Fig.4. Due to the difference between the results of each training result, we have trained the network lots of times and take the every year average prediction as final results. They are shown in Table II.

TABLE II. PRedicted VALUes For the NeXt Five Years

\begin{tabular}{|c|c|c|c|c|c|}
\hline Year & 2014 & 2015 & 2016 & 2017 & 2018 \\
\hline $\begin{array}{c}\text { Predicted } \\
\text { Values } \\
(\mathbf{1 0} \wedge \mathbf{6})\end{array}$ & 3664 & 4420 & 5225 & 6028 & 6770 \\
\hline
\end{tabular}

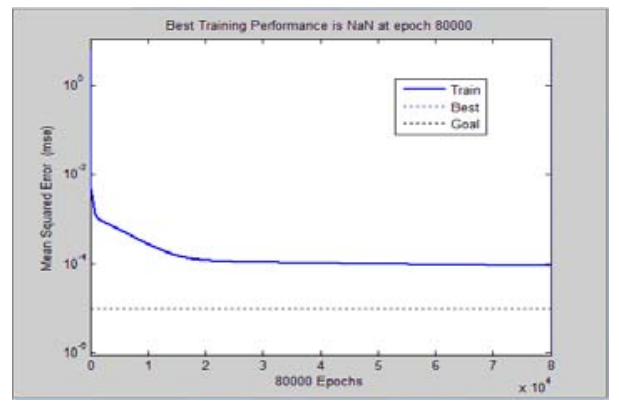

Figure 3. Learning rate of tansig transfer function

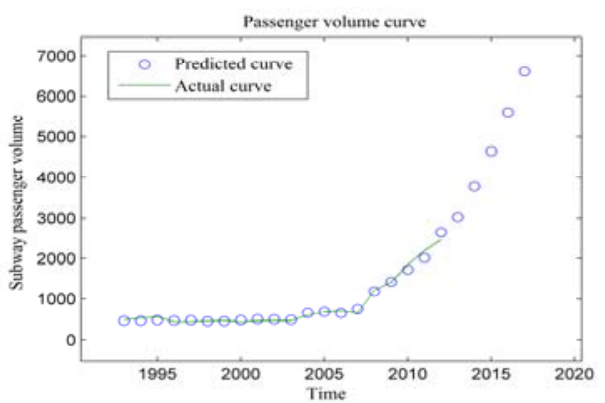

Figure 4. The prediction results of tansig transfer function.

As can be seen from Fig. 3, predicted values obtained by the prediction model are basically close to the actual curve in the past twenty years and the model is well fitted.

We calculate the relative error between predicted values and actual values from year 1993 to 2012, as shown in Table III. The average relative error is $5.56 \%$, which shows that the prescribed precision is relatively high. Results indicate that B-P ANN model is adaptable to the passenger volume prediction and can be adopted as a reference for formulating operational planning of Beijing Subway. From the Predicted values we can see Beijing subway passenger volume increased steadily for the coming years. 


\section{CONCLUSIONS}

The main objective of this article is to provide an improved prediction method to predict passenger volume of Beijing subway, we analyze the factors that influence passenger volume of Beijing subway theoretically at first and selected fifteen factors from four aspects, then used SPSS software to remove factors which are of strong multicollinearity with others, so we establish a three-layer B$\mathrm{P}$ ANN model based on the selected factors to predict the Beijing subway passenger volume for the next five years and ultimately the relative error between the actual and predicted values are calculated. The average value of the relative error is $5.56 \%$, which confirm the feasibility of this method.

TABLE III. The RELATive ERror BEtweEn the PREdicted AND ActuAl VALUES

\begin{tabular}{|l|l|l|l|}
\hline Year & $\begin{array}{c}\text { Actual Values } \\
(\mathbf{1 0} \wedge \mathbf{4})\end{array}$ & $\begin{array}{c}\text { Predicted Values } \\
(\mathbf{1 0} \wedge \mathbf{4})\end{array}$ & $\begin{array}{c}\text { Relative } \\
\text { Error }\end{array}$ \\
\hline 1993 & 49110 & 49110 & $0.00 \%$ \\
\hline 1994 & 53296 & 47400 & $11.06 \%$ \\
\hline 1995 & 55802 & 49660 & $11.01 \%$ \\
\hline 1996 & 44414 & 48140 & $8.39 \%$ \\
\hline 1997 & 44507 & 48720 & $9.47 \%$ \\
\hline 1998 & 46331 & 46330 & $0.00 \%$ \\
\hline 1999 & 48223 & 48220 & $0.01 \%$ \\
\hline 2000 & 43478 & 48510 & $11.57 \%$ \\
\hline 2001 & 46870 & 50440 & $7.62 \%$ \\
\hline 2002 & 48242 & 49270 & $2.13 \%$ \\
\hline 2003 & 47248 & 47250 & $0.00 \%$ \\
\hline 2004 & 60653 & 65650 & $8.24 \%$ \\
\hline 2005 & 67976 & 67980 & $0.01 \%$ \\
\hline 2006 & 70306 & 64880 & $7.72 \%$ \\
\hline 2007 & 65493 & 74520 & $13.78 \%$ \\
\hline 2008 & 121660 & 121700 & $0.03 \%$ \\
\hline 2009 & 142260 & 142300 & $0.03 \%$ \\
\hline 2010 & 184650 & 174600 & $5.44 \%$ \\
\hline 2011 & 219280 & 201800 & $7.97 \%$ \\
\hline 2012 & 246162 & 262900 & $6.80 \%$ \\
\hline & & & \\
\hline
\end{tabular}

As for the convergence speed of B-P ANN is slow AND when a new sample is added in, it would affect the previous studied samples, we need to further explore the practical application of B-P model with other mathematical theory in the future.

In addition, due to the huge subway passenger volume and passenger randomness, a variety of forecasting methods should be combined in order to narrow the gap between the predicted results and the actual values.

\section{ACKNOWLEDGMENT}

The authors appreciate the following funds for their sponsorship on this research, New Century Excellent Talents in University (NCET-13-0655); the National Basic Research Program of China, Grant \#2012CB725406; the Fundamental Research Funds for the Central Universities, Grant \# 2011JBM251.

\section{REFERENCES}

[1] Zhou Weiteng, Han Baoming, and Li Dewei, "Passenger Trafic Volume Forecast for Beijing Subway Based on Back Propagation ANN Model," Urban Rapid Rail Transit. Beijing, 24(2), pp. 50-54, April 2011.

[2] Wang Deng, "Research of quantity of shipments forecasting model based on artificial neuraI network," Logistics Enginering and Management, Wuhan, 31(3), pp. 28-31, March 2009.

[3] Li Mingxu, Ye Yinzhong, and Ma Xianghua, "Appfication of neural network in the subway passenger flow prediction," Mechanical Research \& Application, Shanghai, vol. III, pp. 86-89, May 2012.

[4] Xue Wei, SPSS statistical analysis methods and references, 3rd ed., vol. 8. Beiing: Electronic Industry, 2013, pp. 184-201.

[5] Liu Weiguo, MATLAB programming and application, 2nd ed., vol. 2. Beijing: Higher Education, 2010, pp. 83-96.

[6] Ahmet Erdil, and Erol Arcaklioglu, "The prediction of meteorological variables using artificial neural network," Neural Computing and Applications, New York, vol. 22, pp. 1677-1683, June 2013.

[7] M. Gunasekaran, and K. S. Ramaswami, "Evaluation of Artificial Immune System with Artificial Neural Network for Predicting Bombay Stock Exchange Trends," Journal of Computer Science, Beijing, vol. 7, Issue 7, pp. 967-972, 2011.

[8] V. K. Dhar, A. K. Tickoo, R. Koul, andB. P. Dubey, "Comparative performance of some popular artificial neural network algorithms on benchmark and function approximation problems," Pramana, India, vol. 74, Issue 2, pp. 307-324, February 2010.

TABLE IV. DATA OF FACTORS FROM YEAR 1993 TO 2012

\begin{tabular}{|c|c|c|c|c|c|c|c|c|}
\hline Year & $\begin{array}{c}\text { No. of } \\
\text { Public Buses }\end{array}$ & $\begin{array}{c}\text { No. of } \\
\text { Bus Lines }\end{array}$ & $\begin{array}{l}\text { Length of } \\
\text { Bus Lines } \\
\text { (km) }\end{array}$ & $\begin{array}{l}\text { Bus Passenger } \\
\text { Volume }\left(10^{\wedge} 4\right)\end{array}$ & $\begin{array}{l}\text { No. of } \\
\text { Taxis }\end{array}$ & $\begin{array}{l}\text { Taxi Passenger } \\
\text { Volume }\left(10^{\wedge} 4\right)\end{array}$ & $\begin{array}{l}\text { No. of } \\
\text { Bicycle } \\
(10 \wedge 3)\end{array}$ & $\begin{array}{c}\text { No. of } \\
\text { Subway } \\
\text { Lines }\end{array}$ \\
\hline 1993 & 4890 & 266 & 3491 & 286268 & 46022 & 48770 & 7360 & 2 \\
\hline 1995 & 4984 & 261 & 6790 & 315777 & 56686 & 59600 & 8315 & 2 \\
\hline 1996 & 6427 & 266 & 9484 & 305433 & 59493 & 64895 & 8708 & 2 \\
\hline 1997 & 10044 & 284 & 12320 & 346676 & 59902 & 65386 & 9071 & 2 \\
\hline 2000 & 13604 & 422 & 15584 & 348716 & 62613 & 59770 & 9886 & 2 \\
\hline 2001 & 14803 & 461 & 13126 & 395190 & 61740 & 59846 & 10204 & 2 \\
\hline 2002 & 16939 & 502 & 1576 & 436652 & 62848 & 62848 & 11019 & 3 \\
\hline 2003 & 16753 & 527 & 16017 & 376151 & 62283 & 62283 & 11143 & 4 \\
\hline 2004 & 18451 & 517 & 15133 & 436016 & 51561 & 58758 & 11530 & 4 \\
\hline
\end{tabular}




\begin{tabular}{|l|l|l|l|l|l|l|l|l|}
\hline 2006 & 19522 & 601 & 18468 & 389183 & 66323 & 64121 & 12304 & 4 \\
\hline 2007 & 19395 & 621 & 17353 & 409689 & 66646 & 64111 & 12691 & 5 \\
\hline 2008 & 21507 & 648 & 17857 & 458081 & 66646 & 69000 & 13078 & 8 \\
\hline 2009 & 21716 & 692 & 18270 & 516517 & 66646 & 68000 & 13677 \\
\hline 2010 & 21548 & 713 & 18743 & 505144 & 66646 & 69000 & 9 \\
\hline 2011 & 21628 & 749 & 19460 & 503272 & 66646 & 69600 & 14333 & 14 \\
\hline 2012 & 22146 & 799 & 19547 & 515416 & 66646 & 69900 & 25 & 14919 \\
\hline
\end{tabular}

TABLE V. DATA OF FACTORS FROM YEAR 1993 TO 2012

\begin{tabular}{|c|c|c|c|c|c|c|c|c|}
\hline Year & $\begin{array}{l}\text { Length of } \\
\text { Subway } \\
\text { Lines } \\
(\mathbf{k m})\end{array}$ & $\begin{array}{l}\text { No. of } \\
\text { Subway } \\
\text { Vehicles }\end{array}$ & $\begin{array}{c}\text { Subway } \\
\text { Passenger } \\
\text { Volume } \\
(10 \wedge 4) \\
\end{array}$ & $\begin{array}{c}\text { Urban and } \\
\text { Suburban } \\
\text { Resident } \\
(10 \wedge 3)\end{array}$ & $\begin{array}{c}\text { Employed } \\
\text { Population } \\
(10 \wedge 3)\end{array}$ & $\begin{array}{c}\text { Floating } \\
\text { Population } \\
\left(10^{\wedge} 3\right)\end{array}$ & $\begin{array}{l}\text { Per Capita } \\
\text { Income }\end{array}$ & $\begin{array}{c}\text { Per Capita } \\
\text { Transportation } \\
\text { Expenditure } \\
\text { (yuan) }\end{array}$ \\
\hline 1993 & 40.6 & 323 & 49110 & 6448 & 6278 & 1786 & 3548.0 & 202.7 \\
\hline 1994 & 40.6 & 335 & 53296 & 7062 & 6643 & 1843 & 5086.0 & 203.0 \\
\hline 1995 & 40.6 & 383 & 55802 & 7894 & 6653 & 1953 & 6238.0 & 206.8 \\
\hline 1996 & 40.6 & 401 & 44414 & 8902 & 6602 & 2005 & 7339.0 & 218.8 \\
\hline 1997 & 40.6 & 435 & 44507 & 10050 & 6558 & 2106 & 7862.0 & 229.8 \\
\hline 1998 & 40.6 & 437 & 46331 & 11280 & 6222 & 2332 & 10098.2 & 369.5 \\
\hline 1999 & 53.7 & 491 & 48223 & 12572 & 6186 & 2454 & 10654.8 & 467.9 \\
\hline 2000 & 54.0 & 587 & 43478 & 13636 & 6193 & 2501 & 12560.3 & 604.7 \\
\hline 2001 & 54.0 & 617 & 46870 & 13851 & 6289 & 2628 & 13768.8 & 768.3 \\
\hline 2002 & 75.0 & 641 & 48242 & 14232 & 6792 & 2869 & 13253.3 & 1271.0 \\
\hline 2003 & 114.0 & 692 & 47248 & 14564 & 7033 & 3076 & 14959.3 & 1688.1 \\
\hline 2004 & 114.0 & 892 & 60653 & 14927 & 8541 & 3268 & 17116.5 & 1562.2 \\
\hline 2005 & 114.0 & 968 & 67976 & 15380 & 8780 & 3573 & 19533.3 & 1943.5 \\
\hline 2006 & 114.0 & 967 & 70306 & 15810 & 9197 & 3834 & 22417.0 & 2173.0 \\
\hline 2007 & 142.0 & 1130 & 65493 & 16330 & 9427 & 4197 & 24576.0 & 2689.0 \\
\hline 2008 & 200.0 & 1714 & 121660 & 16950 & 9809 & 4651 & 27678.0 & 2793.0 \\
\hline 2009 & 201.4 & 2014 & 142260 & 17550 & 9983 & 4732 & 30674.0 & 2843.0 \\
\hline 2010 & 336.0 & 2463 & 184650 & 19619 & 10316 & 7047 & 33360.0 & 2933.0 \\
\hline 2011 & 372.0 & 2850 & 219280 & 20186 & 10697 & 7422 & 37124.0 & 3205.0 \\
\hline 2012 & 442.0 & 3685 & 246162 & 20693 & 11073 & 7738 & 41103.0 & 3453.0 \\
\hline
\end{tabular}

